\title{
MODEL OF EMISSION OF EXHAUST COMPOUNDS OF JET AIRCRAFT IN CRUISE PHASE ENABLING TRAJECTORY OPTIMIZATION
}

\author{
Małgorzata PAWLAK ${ }^{*}$, Andrzej MAJKA², Michal KUZNIAR ${ }^{3}$, Jowita PAWLUCZY ${ }^{4}$ \\ ${ }^{1}$ Dept of Ship Operation, Gdynia Maritime University, Poland \\ 2,3,4 Dept of Aircraft and Aircraft Engines, Rzeszow University of Technology, Poland
}

Received 8 October 2018; revised 8 February 2019, 14 April 2019; accepted 28 April 2019

\begin{abstract}
Nowadays, air transport is the most modern and the most dynamically developing branch of transport. This intensive development of air transport causes the continuous increase in emissions of pollutants, mainly greenhouse gases, leading to the deepening of the greenhouse effect, which in turn leads to irreversible global climate change. In order to optimize air communication and make it even more economical and environmentally friendly, such activities as e.g. SESAR project are undertaken. One of the parts of this project is the research on minimizing fuel consumption and emissions of pollutants in jet engine exhausts. The paper presents a developed model of emission and main pollutants $\left(\mathrm{NO}_{\mathrm{x}}, \mathrm{CO}, \mathrm{HC}\right.$ and $\mathrm{CO}_{2}$ ) in the exhausts of jet engines of a passenger aircraft during a cruise phase. Applying simple optimization tools, such as e.g. the Dijkstra's algorithm, this model was verified by the optimization of a trajectory of a jet aircraft in a cruise phase on an exemplary route in terms of minimizing emission of selected harmful compounds in jet engines exhausts. To meet the aim of the research, it was necessary to develop a computer program that determines a two-dimensional grid graph, assigns its appropriate weights to its edges and passing along these edges, determines the optimal trajectory of a given flight between two indicated start and end vertices. The developed research methodology is universal and can be applied for any jet passenger aircraft.
\end{abstract}

Keywords: aircraft, jet engine, emission, fuel consumption, flight path, trajectory optimization, cruise phase.

\section{Notations}

Abbreviations:

ATM - air traffic management;

EASA - European aviation safety agency;

ECAC - European civil aviation conference;

ICAO - International civil aviation organisation;

EI - emission index;

EU - European Union;

EUROCONTROL - European organisation for the safety of air navigation;

IFR - instrument flight rules;

ISA - International standard atmosphere;

LTO - landing and take-off operations;

NMVOCs - non-methane volatile organic compounds;

PC - personal computer;

SES - single European sky;
SESAR - SES ATM research;

TAS - true air speed;

VOG - velocity over ground.

Variables, parameters and functions:

$\alpha_{\text {wind }}$ - angle between the flight direction and the wind direction $\left[^{\circ}\right]$.

$\delta$ - pressure change coefficient $[-]$;

$\theta$ - temperature change coefficient $[-]$;

$\omega$ - specific humidity, where $\omega=10^{-3} \cdot e^{-0.0001426 \cdot(H-12900)}$ for ISA, where $H$ - cruising altitude in units of feet;

$C_{x}-$ drag coefficient [-]

$C_{z}$ - lift coefficient [-]

$e$ - Euler number $(e=2.72)$;

$E_{\mathrm{NO}_{\mathrm{x}}}, E_{\mathrm{CO}}$,

$E_{\mathrm{HC}}, E_{\mathrm{CO}_{2}}$,

$E_{\mathrm{H}_{2} \mathrm{O}}, E_{\mathrm{SO}_{\mathrm{x}}}$ - emission of particular compounds in the exhausts [kg];

${ }^{*}$ Corresponding author. E-mail: m.pawlak@wn.umg.edu.pl 


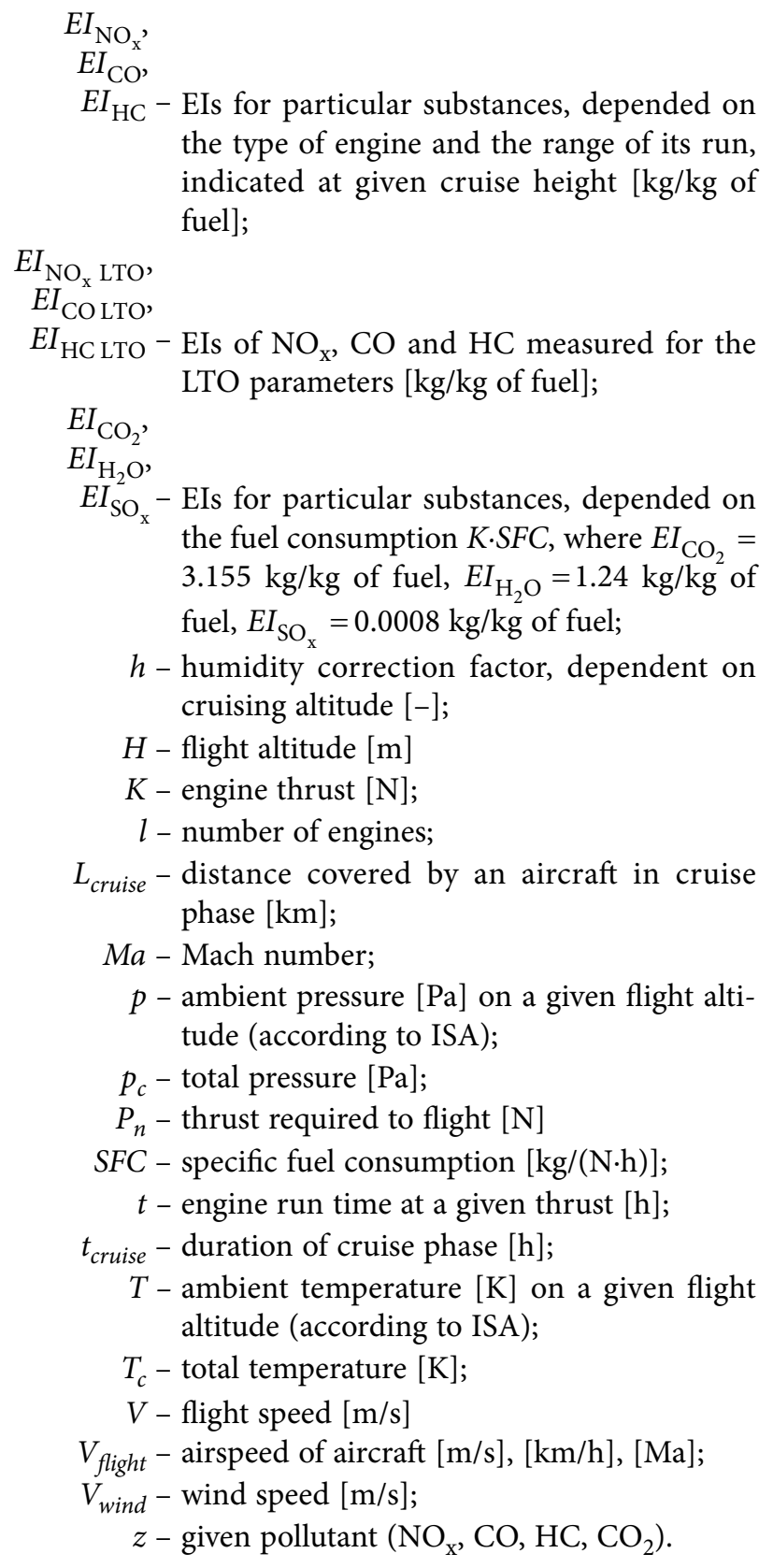

\section{Introduction}

Air transport definitely plays a crucial role in the economic development of the world. Simultaneously, however, it constitutes the source of problems on a global and local scale, among which there can be distinguished the adverse impact of aircraft and airports on the natural environment and the population living in areas with high traffic intensity. These adverse effects of air transport are mainly due to noise and harmful emissions. The main sources of these emissions are the propulsion engines of aircraft emitting carbon dioxide, carbon monoxide, sulphur dioxide, nitrogen oxides and particulate matter, as well as methane and nitrous oxide. These emissions depend on the fuel type, aircraft type, engine type and operating conditions (altitude, speed, level of power or thrust etc.).
Operations carried out by aircraft are usually divided into two main groups:

- LTO, covering all tasks performed by an aircraft in the airport area and its vicinity, below $3000 \mathrm{ft}$ (about $1000 \mathrm{~m}$ ), these stages include taxiing, take-off, climbing after take-off, approach to landing and landing;

- cruise, which is defined as a set of all tasks performed by an aircraft above a height of $3000 \mathrm{ft}$ (about $1000 \mathrm{~m}$ ).

The pollutants emitted during LTO are the combustion products released during: stopping (with working engines), taxiing on the apron (to and from the runway), take-off and climb, approach to landing and landing. The load of pollutants emitted in the cruise phase depends on the route length. Table 1 presents the average emission of harmful compounds in the exhausts (calculated per $1 \mathrm{t}$ of fuel consumed in this phase) for medium-sized aircraft, performing flights on short (local) or medium (continental) routes, both for modern and older constructions.

Despite the fact that aviation participates to a small extent $(2 \ldots 3 \%)$ in global environmental pollution (Głowacki, Szczeciński 2013; Jeż 2009), the concentration of greenhouse gases and toxic compounds emitted by aircraft engines and support equipment is particularly large in the airport areas (LTO) and in the upper troposphere (cruise). This impact is the stronger the more intensive air traffic takes place in a given area.

Europe, and in particular the EU, is one of the most densely populated areas on earth. There are about 1270 airports on its area, nearly 750 of which are able to perform regular commercial flights (Brusow et al. 2007).

Every day, around 27000 controlled flights are carried out in the European airspace, and 440 airports serve around 800 million passengers annually. In 2015, over 9.9 million IFR operations were carried out in Europe, and an increase by $16 \%$ by 2022 is forecasted (Table 2). $80 \%$ of these flights are within the EU (EUROCONTROL 2016a).

Out of all air operations in Europe, $44 \%$ are carried out at the 25 largest airports, while $70 \%$ of all passenger traffic goes through the 15 largest airports (EUROCONTROL 2016a, 2016b, 2018; SESAR 2018; PANSA 2018). This results in high density of air traffic at the largest airports and their vicinity. Also in these areas, the greatest adverse impact of air transport on the natural environment is observed.

Europe is faced a crisis in airspace capacity, as it is predicted that the number of flights will increase by as much as $50 \%$ in the next $10 \ldots 20$ years. Another problem is the low efficiency of using the European airspace, caused by its fragmentation and its inefficient management.

The existing rules of flight planning make flight plans rarely in line with their operational implementation. The effect of this is the low predictability of air traffic, affecting the heavy burden of air traffic controllers in resolving conflict situations and long delays in air traffic. The shortage of the possibility of effective route optimization during the flight planning stage makes the European flight routes extended by an average of $42 \mathrm{~km}$ compared to optimal 
Table. 1. Average fuel consumption and emission for medium-sized aircraft for the LTO phase and cruise phase (ICAO 2008; IPCC 1997)

\begin{tabular}{|c|c|c|c|c|c|c|c|c|}
\hline & Fuel & $\mathrm{SO}_{2}$ & $\mathrm{CO}$ & $\mathrm{CO}_{2}$ & $\mathrm{NO}_{\mathrm{x}}$ & NMVOCs & $\mathrm{CH}_{4}$ & $\mathrm{~N}_{2} \mathrm{O}$ \\
\hline \multicolumn{9}{|c|}{ Short routes } \\
\hline LTO [kg/LTO] - modern aircraft & 850 & 0.8 & 8.1 & 2680 & 10.2 & 2.6 & 0.3 & 0.1 \\
\hline LTO [kg/LTO] - older aircraft & 1000 & 1.0 & 17 & 3150 & 9.0 & 3.7 & 0.4 & 0.1 \\
\hline Cruise $[\mathrm{kg} / \mathrm{t}]$ & - & 1.0 & 7 & 3150 & 11 & 0.7 & 0 & 0.1 \\
\hline \multicolumn{9}{|c|}{ Medium-length routes } \\
\hline LTO [kg/LTO] - modern aircraft & 2400 & 2.4 & 50 & 7560 & 23.6 & 15 & 1.5 & 0.2 \\
\hline LTO [kg/LTO] - older aircraft & 2500 & 2.5 & 101 & 7900 & 41 & 66 & 7 & 0.2 \\
\hline Cruise $[\mathrm{kg} / \mathrm{t}]$ & - & 1.0 & 5 & 3150 & 17 & 2.7 & 0 & 0.1 \\
\hline
\end{tabular}

solutions, which in consequence means higher fuel consumption, increased pollutants emission and higher costs for the users (EUROCONTROL 2016b; SESAR 2018).

The answer to these problems was the initiation of the SESAR program, which is a technological pillar of SES (SESAR 2018; PANSA 2018). The aim of this program is to develop and implement a modern ATM system, allowing to increase ATM network capacity to meet the everincreasing number of flight operations while improving economic as well as safety and security indicators. The use of modern technologies and procedures will also help reduce the negative impact of air transport on the natural environment.

One of the manners to reduce the adverse impact of aircraft on the natural environment is the appropriate indicating of flight routes, minimizing the emission of harmful substances in jet engines exhausts. This requires proper flight planning, taking into account the limitations resulting from the organization of the airspace and the rules therein, as well as the current weather conditions. The weather is one of the most important factors affecting the amount of fuel used, time and cost of the flight. The computational algorithm, which determines the fuel mass, flight time and finally its emission, should use the best weather forecasts available at the planning stage. This will allow to minimize the estimation error of the parameters and to optimize the flight route taking into account the most favourable conditions for its implementation. In addition to typical parameters, such as pressure and air density, special attention must be paid to the correct determination of temperature and speed and direction of the

Table 2. Total number of IFR flights within Europe (ECAC area) - forecast: $\mathrm{M}$ - medium, $\mathrm{H}$ - high, $\mathrm{L}$ - low (EUROCONTROL 2016a)

\begin{tabular}{|l|c|c|c|c|c|}
\hline \multicolumn{2}{|c|}{ ECAC area } & 2016 & 2018 & 2020 & 2022 \\
\hline \multirow{2}{*}{$\begin{array}{l}\text { IFR } \\
\text { flights }\end{array}$} & $\mathrm{H}$ & 10293000 & 11092000 & 11997000 & 12868000 \\
\cline { 2 - 6 } & $\mathrm{M}$ & 10153000 & 10578000 & 11091000 & 11535000 \\
\cline { 2 - 6 } & $\mathrm{L}$ & 10023000 & 10140000 & 10335000 & 10440000 \\
\hline \multirow{2}{*}{$\begin{array}{l}\text { Annual } \\
\text { growth } \\
{[\%]}\end{array}$} & $\mathrm{H}$ & $3.8 \%$ & $4.3 \%$ & $4.3 \%$ & $3.6 \%$ \\
\cline { 2 - 6 } & $\mathrm{M}$ & $2.4 \%$ & $2.1 \%$ & $2.5 \%$ & $2.1 \%$ \\
\cline { 2 - 6 } & $\mathrm{L}$ & $1.1 \%$ & $0.3 \%$ & $1.0 \%$ & $0.6 \%$ \\
\hline
\end{tabular}

wind. The speed of sound depends on the temperature, which enables to determine correctly the Mach number for a plane flying at a given TAS. The speed and direction of the wind has an effect on the speed of the aircraft relative to the ground, i.e. VOG.

Planning a flight that minimizes emissions or fuel consumption is a difficult and demanding task, due to the complexity of the conditions that have to be taken into account (airspace structure, restrictions, location of prohibited zones, traffic conditions and weather forecast). It can be done only with the use of an appropriate computational system. The flight planning system must rely on appropriate computational models for: aircraft, airspace, flight route, air traffic and weather (Kopecki et al. 2017). In addition, there must be the access to current weather conditions and information on current and planned air traffic and the airspace condition.

The aim of the paper is to portray a model developed for the determination of emissions of selected pollutants in the exhausts of passenger jet aircraft in the cruise phase. The developed approach will enable to use this method to determine the emission of pollutants in the exhausts of aircraft engines in the cruise phase and e.g. to optimize the aircraft's trajectory in terms of minimizing these emissions in this flight phase.

\section{State-of-the-art}

Globally, many attempts are made to analyse the impact of air transport on the environment in local, regional or global scale, e.g. Archer (2001), Garrison et al. (2003), Kim et al. (2007); Khardi and Kurniawan (2012), Masiol and Harrison (2014), Penner et al. (1999), Ramanathan and Feng (2009), Schäfer and Waitz (2014), Elbir (2008), WHO (2006). Most of these studies are of a general nature - they treat in general terms the problem of gaseous emission in jet engines exhausts and their impact on the environment, climate change and human health.

It is worth noting that many studies focus on determining this impact in the area or vicinity of airports during the LTO operation, where apart from emissions of harmful compounds in the exhausts, the problem of noise generation occurs. Due to the availability of data on $\mathrm{NO}_{\mathrm{x}}$, $\mathrm{CO}$ and HC EIs in the ICAO databases (EASA 2018) for 
aircraft engines with a thrust value of above $26.7 \mathrm{kN}$, it is possible to compute the emissions of these compounds for individual aircraft. Having data on air traffic at a given airport, it is also possible to determine the total emissions of particular compounds for a given airport in a given period of time, e.g. a year (Elbir 2008). It is also possible to make some analyses for only one selected LTO phase, e.g. climb, in order to determine the emission (Serafino 2014).

There are also made attempts to determine emissions during the cruise phase, for larger airplanes (Hamy et al. 2016), as well to optimize the route of the aircraft or selected flight parameters or aircraft configuration due to the fuel consumption, exhaust emissions and noise from aircraft engines, including e.g. Antoine and Kroo (2004), Serafino (2014), Hamy et al. (2016), Bower and Kroo (2008), Singh and Sharma (2014), Singh (2017).

It should be noted that in numerous works attempts are made to determine emissions only of some harmful compounds, or even just one of them $-\mathrm{CO}_{2}$ (which is related to fuel consumption), while omitting other substances and disregarding the change of engine work parameters with the change of ambient conditions (including cruising altitude, air temperature and pressure). Most scientific studies are very vague and do not take into account the engines performance characteristics.

On the basis of the literature review, it can be stated that for small business jet aircraft of a thrust of $26.7 \mathrm{kN}$ and lower there is currently conducted very limited research, if any, on the impact on the environment and the possibility of reducing it, e.g. by planning, optimization or modifying the aircraft trajectory in the cruise phase. This is mainly due to the fact that in the past decades there was minor interest in so-called small aviation. For this reason, in available databases referring to EIs, e.g. ICAO database, generally no business aircraft engines are included. This is a major obstacle in the estimation of emissions from aircraft engines of this type.

Due to the fact that current research is mostly limited to the estimation of emissions in the LTO phase, it seems expedient to study emissions in the cruise phase. The largest amount of pollutants is introduced in higher atmosphere $(8 \ldots 12 \mathrm{~km}$ above sea level), i.e. on altitudes where long-haul flights take place. It is estimated that only $5 . . .10 \%$ of global aviation fuel consumption occurs on low altitudes (up to $1 \mathrm{~km}$ ) (Kim et al. 2007). Emission during the LTO phase interacts locally - within the airport and its vicinity, while the emission in the cruise phase applies constitutes a global ecological problem. This is all the more important because the pollution that is generated during the cruise phase affects a large area and can persist in the upper atmosphere, affecting the formation of clouds. Due to the lack of coherent models taking into account the emission of various pollutants in jet engine exhausts, there is a need to develop a model for flights on high altitudes on different routes, taking into account wind direction and force. This model would also include determining the real flight trajectory for the cruise phase taking into account meteorological conditions. The pur- pose of the presented research is to develop such a computational model that could be used for various passenger jet aircraft equipped with jet by-pass engines.

\section{Developing a model of exhausts emission for a jet aircraft in cruise phase}

The development of a model of $\mathrm{NO}_{\mathrm{x}}, \mathrm{CO}, \mathrm{HC}$ and $\mathrm{CO}_{2}$ emissions in the exhausts of passenger jet aircraft equipped with by-pass jet engines, intended for the cruise phase, requires determining the assumptions resulting from the limitations of the applicability of the model. The limitations of this model are:

- scope of applicability: for passenger aircraft equipped with by-pass jet engines;

- cruising altitude: up to $11 \mathrm{~km}$ - due to the range of correctness of the functioning of the formulas for the determination of EI and the aircraft performance parameters - limitations resulting from the use of formulas describing ISA to determine the ambient parameters (pressure and temperature during the flight at a specific altitude);

- flight speed: up to $0.9 \mathrm{Ma}$ - due to the range of work of by-pass engines used in passenger aircraft and the maximum speed of this group of aircraft.

To determine the emission of a given pollutant $z$ in the exhausts of the aircraft engines, the following formula can be used:

$E_{(z)}=E I_{(z)} \cdot K \cdot S F C \cdot t \cdot l$.

The thrust and specific fuel consumption can be read directly from the engine characteristics. In order to determine the EIs for a given flight phase, the EIs for the LTO phase should be reduced to the ambient flight parameters, depending on the flight speed and altitude.

Measuring these values during the flight is very difficult, but analytical approximation of these values is possible. The speed and altitude characteristics for jet engines can be approximated by means of appropriate transformation of the rotational characteristics of the jet engine.

The dependencies describing the change in ambient pressure and ambient temperature due to changes in altitude and flight speed can be written as follows (Wilson, Korakianitis 2014):

$$
\begin{aligned}
& T_{c}=T \cdot\left(1+0.2 \cdot M a^{2}\right) ; \\
& p_{c}=p \cdot\left(1+0.2 \cdot M a^{2}\right)^{3.5} .
\end{aligned}
$$

On this basis, the formulas for the reduction of EIs of particular pollutants can be derived (Schaefer, Bartosch 2013):

$$
\begin{aligned}
& E I_{\mathrm{NO}_{\mathrm{x}}}=E I_{\mathrm{NO}_{\mathrm{x}} \mathrm{LTO}} \cdot \sqrt{\frac{\delta^{1.02}}{\theta^{2.2}}} \cdot e^{h} ; \\
& E I_{\mathrm{CO}}=E I_{\mathrm{CO} \mathrm{LTO}} \cdot \frac{\theta^{2.2}}{\delta^{1.02}} ; \\
& E I_{\mathrm{HC}}=E I_{\mathrm{HC} \mathrm{LTO}} \cdot \frac{\theta^{2.2}}{\delta^{1.02}} ;
\end{aligned}
$$




$$
\begin{aligned}
& \theta=\frac{T_{c}}{288.15 \cdot K} ; \\
& \delta=\frac{p_{c}}{101325} ; \\
& h=-19 \cdot(\omega-0.00634) .
\end{aligned}
$$

EI for $\mathrm{CO}_{2}\left(\mathrm{EI}_{\mathrm{CO}_{2}}\right)$ is constant and equal to $3.1555 \mathrm{~kg} / \mathrm{kg}$ of fuel burned for each jet engine, because this is proportional to fuel consumption.

Having determined the EIs for the pollutants considered $E I_{(z)}$, it is possible to determine the emission intensity of a given pollutant $z$ that is generated by the $l$-engines of the aircraft, using the formula:

$$
\dot{E}_{(z)}=E I_{(z)} \cdot K \cdot S F C \cdot l \text {. }
$$

The developed model of emissions and a pollutant $z$ in the passenger jet engine's exhausts is shown graphically in Figure 1.

Multiplying the emission intensity by the flight time in cruise phase, the amount of emitted pollution $z$ for a given aircraft in the mass unit [e.g. $\mathrm{kg}$ ] is obtained, i.e. the emission:

$$
E_{(z)}=\dot{E}_{(z)} \cdot t
$$

Application of the developed model of emission of pollutants in the je engines' exhausts requires using the performance characteristics of the engines used in a given jet aircraft. The $\mathrm{CO}_{2}$ emissions can be simply determined - based on the amount of fuel burnt during the cruise phase. Unfortunately, the emission of other compounds $\left(\mathrm{NO}_{\mathrm{x}}, \mathrm{CO}\right.$ and $\left.\mathrm{HC}\right)$ is strongly dependent on a number of parameters, especially on the type of engine, its power settings, current flight speed, altitude and ambient atmospheric conditions.

The wind speeds and directions must be taken into account when determining the emission, because they affect the duration of the flight - its shortening in the case of tailwinds and its elongation in the case of headwinds. Duration of the flight in the cruise phase, affects the total emission of harmful compounds in the exhausts.

The determination of flight time requires solving the problem of the impact of wind on the speed of the aircraft relative to the ground. The speed of the aircraft is given in relation to the airflow. Taking into account the angle between the direction of the flight and the direction of the wind, there can be determined the speed by which the speed of the aircraft relative to the ground will increase or decrease. Taking into account the distance covered by the aircraft, there can be determined the total time of flight in cruise phase:

$$
t_{\text {cruise }}=\frac{L_{\text {cruise }}}{V_{\text {flight }} \pm V_{\text {wind }} \cdot \cos \alpha_{\text {wind }}} .
$$

\section{Verification of the developed model of emission}

The verification of the computational model of emission consisted in using it to determine the trajectory characterized by minimal emission. The verification was carried out using empirical research methods, which mainly consisted of numerical simulations. The performance model of a power unit was validated using empirical research methods that consisted of numerical experimental studies carried out using the DGEN engine virtual bench. The minimum emission was obtained by the application of optimization. To determine the optimal trajectory, taking into account the meteorological conditions, the classical form of the Dijkstra's algorithm was used (Dijkstra 1959), modelling the airspace with a graph with evenly distributed vertices and edges connecting all neighbouring vertices. The emission computational model, the airspace model and the computational algorithm were implemented in the MATLAB (https://www.mathworks.com) environment, using its built-in functions for optimization with the Dijkstra's algorithm.

Verification of the developed model of emission requires the adoption of an exemplary route and an exemplary aircraft.

\subsection{Adoption of a flight route}

For the research reasons, the route between two Polish cities: Gdansk and Rzeszow, was adopted. For this route, the cruise phase of a length of $384 \mathrm{~km}$ was designated (Figure 2), for which a cruising altitude of $10000 \mathrm{~m}$ and a cruising speed of $0.8 \mathrm{Ma}$ were assumed.

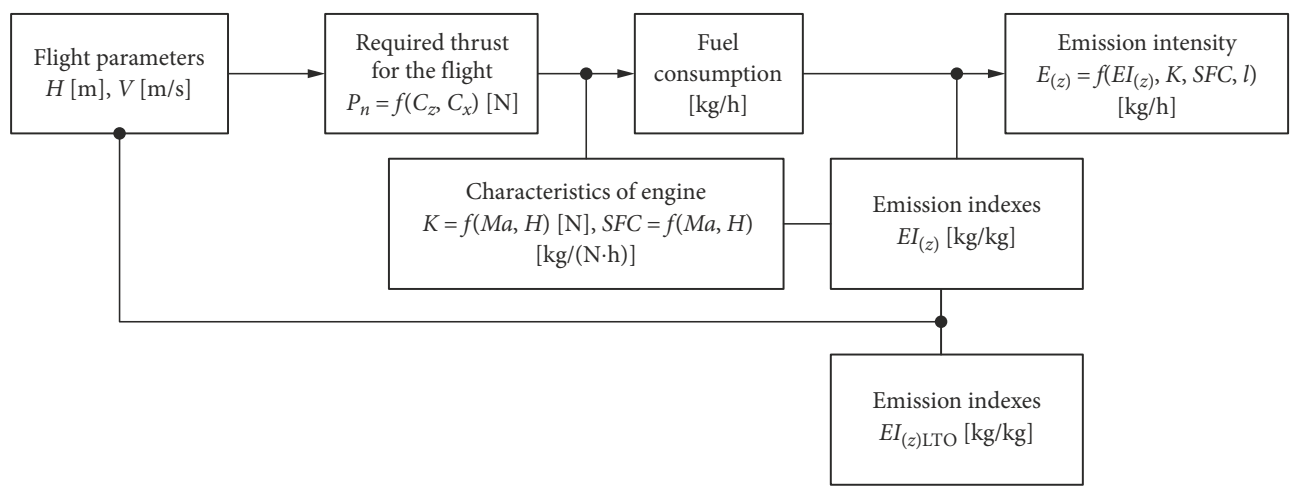

Figure 1. Block diagram of the model of emission 
The airspace between these cities was divided at the altitude of $10000 \mathrm{~m}$ into 42 squares with a side length of $24 \mathrm{~km}$. This set of squares together with their diagonals formed a grid - the edges of the graph along which the plane could travel from the starting point to the destination one. The weights were assigned to the edges of the graph. These weights were corresponding to the time required to go along a given edge. Time for the flight was determined taking into account the speed and direction of the wind. A map showing the route between the cities to be covered by a plane with the graph edges constituting all possible paths is shown in Figure 3.

\subsection{Adoption of an aircraft and experimental validation of its engines characteristics}

The research was conducted for an exemplary business jet aircraft - Gulfstream IV, equipped with two Rolls Royce TAY-611C engines.

The speed and altitude characteristics of these engines were determined on the basis of available engine technical data (EASA 2013).

The method of obtaining the characteristics of the Rolls Royce TAY-611C engine was validated by determining the characteristics of the DGEN 380 engine according to the same procedure. Next, the obtained results were compared with the simulation results on the virtual engine test bench WESTT CS/BV.

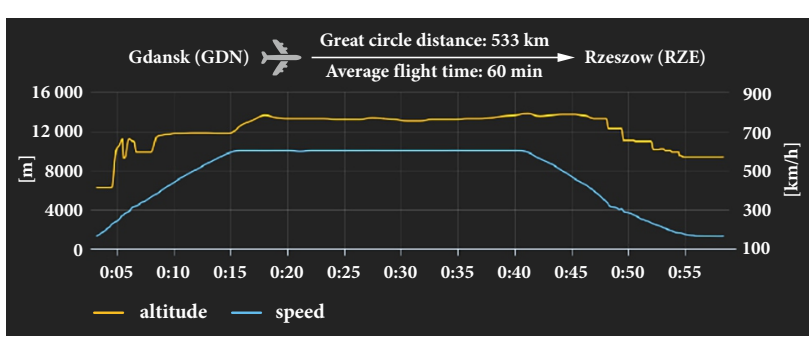

Figure 2. Adopted trajectory of flight between Rzeszow and Gdansk, developed basing on Flightradar24 (2018)

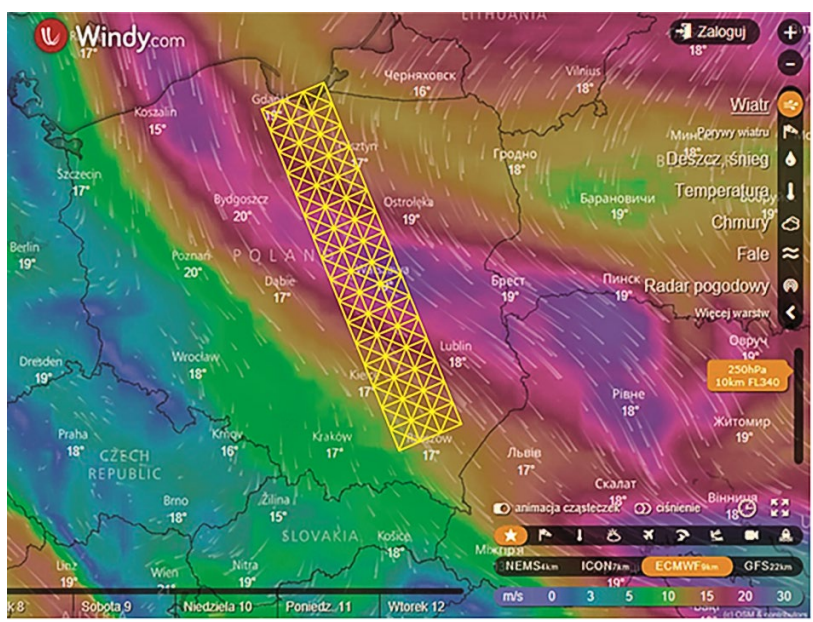

Figure 3. A map of meteorological conditions at the flight altitude of $10 \mathrm{~km}$, extracted from Windy (2018), with the graph edges and vertices indicated (meteorological data retrieved from Windy (2018) on 6 June 2018)
The DGEN 380 engine is the engine designed for business jet aircraft. Hence, it shows structural similarities to the Rolls Royce TAY-611C engine - it is also a by-pass engine.

Therefore, it can be concluded that the overall course of the speed and altitude characteristics functions of the DGEN 380 engine will be similar to the characteristics of the Rolls Royce TAY-611C engine used for the model validation. Hence, it can be concluded that the applied method for determining the performance of aircraft engines is correct and can be used for the engines similar in construction to DGEN 380 engine.

Having determined the optimal total flight time, which is the sum of flight times on the edges of the graph and taking into account the aircraft performance parameters, as well as the EIs obtained in earlier research and applying the Formulas (1)-(12), the emissions of some pollutants in the engines exhausts, such as $\mathrm{NO}_{\mathrm{x}}, \mathrm{CO}, \mathrm{HC}$ and $\mathrm{CO}_{2}$, were determined.

The adopted engine operating parameters correspond to the demand for the thrust required for the flight of the aircraft, with its known aerodynamic characteristics, mass, flight velocity and altitude. The details of methodology and selection of engine operating parameters are included in earlier papers in the series (Pawlak, Kuźniar 2018; Pawlak et al. 2018a, 2018b).

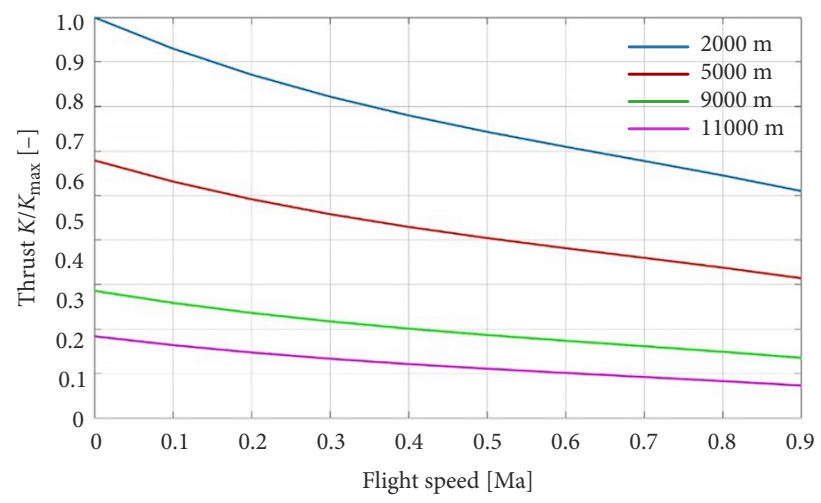

Figure 4. The thrust of the Rolls Royce TAY-611C engine as a function of altitude and flight speed for different flight altitudes

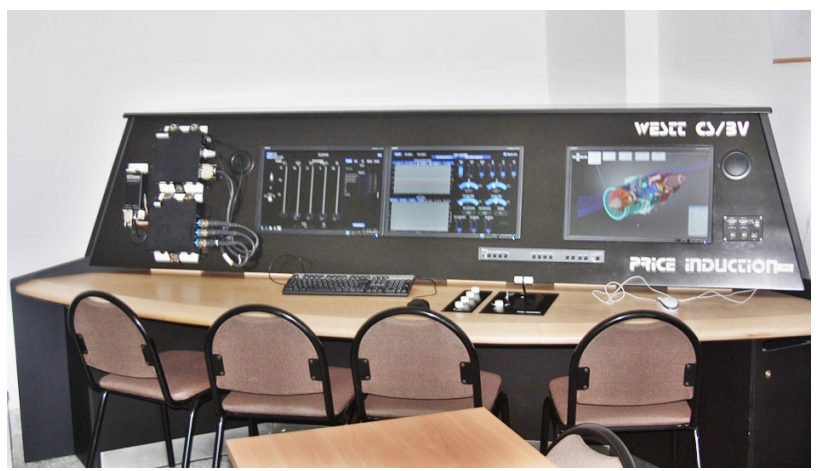

Figure 5. Virtual engine test bench WESTT CS/BV, the measurement data is displayed on the screens 


\subsection{Results of the research conducted for different flight variants}

The research was carried out for two flight variants - a route with wind (Gdansk-Rzeszow) and an upwind route (Rzeszow-Gdansk). In both cases, the meteorological conditions were the same, but the direction of the wind impact on the aircraft was different. The results obtained for these two flight variants are summarized in Table 3.

In the case of the flight from Rzeszow to Gdansk, which took place in less favourable weather conditions, the flight time extended by $2.5 \mathrm{~min}$, resulting in an increase in emissions by $11 \%$.

\subsection{The trajectory optimisation - results and discussion}

This new approach to determination of emissions in the engines exhausts of the aircraft during its cruise phase for various meteorological conditions, with the application of a graph can be used for further analysis. One of such tests may be, for example, optimization of the aircraft's trajectory due to the minimization of emissions of harmful compounds in the exhaust of their engines.

The next part of the paper presents the use of the developed model to determine the shortest path, i.e. the optimal path (trajectory) for a given route. For this reason, the MATLAB was used, together with its built-in functions: Dijkstra's algorithm and shortest path (Dijkstra 1959; Pratap 2016). This analysis was performed on a PC with sufficient computing power to solve this problem.

Both the graph and the weights of its edges, as well as the optimized trajectory were determined by a program written by the authors of this paper.

The path is an orderly sequence of successive edges to go through from the start vertex, i.e. in the analysed case - the point determining the beginning of the cruise phase, to the end vertex, i.e. in the analysed case - the point determining the end of the cruise phase. There may be many different paths in the graph between the two selected vertices. Paths can also be defined using a sequence of consecutively passing vertices (it is obvious that each two successive vertices must be linked with an edge). The distances between vertices are the edge weights.

Having a given graph with the selected vertex (source), the Dikstra's algorithm finds the distance from the source to all other vertices. It is easy to modify it so that it searches only the shortest path to one fixed vertex, simply interrupting the action when reaching the target vertex, or transposing the graph's incident table.
The application of the Dijkstra's algorithm allows to find in the graph all the shortest paths between the selected vertex and all the other ones, while also computing the total value, e.g. the transition time of each of these paths.

Based on the developed program, different flight trajectories were determined in terms of minimizing emissions of harmful compounds. In the case of a flight from Gdansk to Rzeszow, and therefore with favourable wind conditions, four exemplary trajectories were presented (three of which are optimized), which started in different vertices of the grid described above.

The presented trajectories show how key role plays the proper selection of the starting and ending point of the assumed route. In real conditions, it will not always be possible to choose the optimal starting point and end point, because these points are geographically determined (location of airports as well as the take-off and approach options), however, theoretically, it is possible to make optimization for any previously chosen starting and ending point.

In Table 4, and Figures 6 and 7 there are presented three exemplary trajectories of cruise phase for Gulfstream flying from Gdansk to Rzeszow, which are compared with a reference trajectory (non-optimised one). These trajectories were determined based on real conditions (meteorological data) that in the time of the analysis were favourable (tailwind). Cruising time and emission of main pollutants were determined for each trajectory considered.

As it can be noted, the most optimal in terms of the shortest flight time and the lowest emission would be trajectory No 4 .

Emissions with favourable wind but without trajectory optimization is presented in red (No 1). Due to the optimization it was possible to obtain trajectories of lower emissions and lower flight duration for the same input data considered (No 2, 3 and 4). Table 5 summarizes the obtained research results for the non-optimized and the optimized trajectory of the lowest emission (trajectory No 4).

A similar analysis was made for the return journey, assuming no change in meteorological conditions, which means that in this case the plane travelled upwind (Table 6, and Figures 8 and 9).

Conducting similar analysis as in the case of flight with the wind, the most optimal trajectory for the flight from Rzeszow to Gdansk in terms of the lowest emissions and geographical location of the airports is trajectory No 8 . As in the previous case, the obtained emission values can be compared to the non-optimised route of the aircraft. The results of this comparison are shown in Table 7.

Table 3. Cruising time and corresponding total amount of $\mathrm{NO}_{\mathrm{x}}, \mathrm{CO}, \mathrm{HC}$ and $\mathrm{CO}_{2}$ emitted in the cruise phase during the flight from Gdansk to Rzeszow and from Rzeszow to Gdansk

\begin{tabular}{|c|c|c|c|c|c|}
\hline \multirow[b]{2}{*}{ Route } & \multirow[b]{2}{*}{ Cruising time $t_{\text {cruise }}[\mathrm{min}]$} & \multicolumn{4}{|c|}{ Emission } \\
\hline & & $E_{\mathrm{NO}_{\mathrm{x}}}[\mathrm{kg}]$ & $E_{\mathrm{CO}}[\mathrm{kg}]$ & $E_{\mathrm{HC}}[\mathrm{kg}]$ & $E_{\mathrm{CO}_{2}}[\mathrm{~kg}]$ \\
\hline Gdansk-Rzeszow & 25.32 & 25.45 & 1.70 & 0.2191 & 2336 \\
\hline Rzeszow-Gdansk & 28.10 & 28.25 & 1.89 & 0.2432 & 2593 \\
\hline
\end{tabular}


Table 4. Cruising time and corresponding total amount of $\mathrm{NO}_{\mathrm{x}}, \mathrm{CO}, \mathrm{HC}$ and $\mathrm{CO}_{2}$ emitted on three optimised and a reference trajectories in the cruise phase during the flight from Gdansk to Rzeszow

\begin{tabular}{|l|c|c|c|c|c|c|c|}
\hline \multirow{2}{*}{ No of trajectory } & \multirow{2}{*}{$\begin{array}{c}\text { No of start } \\
\text { vertex }\end{array}$} & \multirow{2}{*}{$\begin{array}{c}\text { No of end } \\
\text { vertex }\end{array}$} & $\begin{array}{c}\text { Cruising time } \\
t_{\text {cruise }}[\mathrm{min}]\end{array}$ & $E_{\mathrm{NO}_{\mathrm{x}}}[\mathrm{kg}]$ & $E_{\mathrm{CO}}[\mathrm{kg}]$ & $E_{\mathrm{HC}}[\mathrm{kg}]$ & $E_{\mathrm{CO}_{2}}[\mathrm{~kg}]$ \\
\hline No 1 (Figure 3): reference & 4 & 61 & 25.32 & 25.45 & 1.70 & 0.2191 & 2336 \\
\hline No 2 (Figure 3): optimised & 1 & 64 & 25.18 & 25.30 & 1.69 & 0.2178 & 2323 \\
\hline No 3 (Figure 4): optimised & 2 & 63 & 23.98 & 24.10 & 1.61 & 0.2075 & 2212 \\
\hline No 4 (Figure 4): optimised & 1 & 61 & 23.46 & 23.58 & 1.58 & 0.2030 & 2165 \\
\hline
\end{tabular}

Table 5. The difference (numerical and percentage) between flight parameters (its duration) and the emission of selected pollutants in the exhausts on optimized trajectory No 4 in relation to the non-optimized trajectory No 1 (non-optimized trajectory $=100 \%$ ) on the Gdansk-Rzeszow route

\begin{tabular}{|c|c|c|c|c|c|c|c|c|c|}
\hline$t_{\text {cruise }}[\mathrm{min}]$ & $t_{\text {cruise }}[\%]$ & $E_{\mathrm{NO}_{\mathrm{x}}}[\mathrm{kg}]$ & $E_{\mathrm{NO}_{\mathrm{x}}}[\%]$ & $E_{\mathrm{CO}}[\mathrm{kg}]$ & $E_{\mathrm{CO}}[\%]$ & $E_{\mathrm{HC}}[\mathrm{kg}]$ & $E_{\mathrm{HC}}[\%]$ & $E_{\mathrm{CO}_{2}}[\mathrm{~kg}]$ & $E_{\mathrm{CO}_{2}}[\%]$ \\
\hline-1.86 & -7.35 & -1.87 & -7.35 & -0.12 & -7.01 & -0.0161 & -7.35 & -171 & -7.32 \\
\hline
\end{tabular}

Table 6. Cruising time and corresponding total amount of $\mathrm{NO}_{\mathrm{x}}, \mathrm{CO}, \mathrm{HC}$ and $\mathrm{CO}_{2}$ emitted on three optimised and a reference trajectories in the cruise phase during the flight from Rzeszow to Gdansk

\begin{tabular}{|c|c|c|c|c|c|c|c|}
\hline \multirow[b]{2}{*}{ No of trajectory } & \multirow{2}{*}{$\begin{array}{l}\text { No of start } \\
\text { vertex }\end{array}$} & \multirow{2}{*}{$\begin{array}{l}\text { No of end } \\
\text { vertex }\end{array}$} & \multirow{2}{*}{$\begin{array}{c}\text { Cruising time } \\
t_{\text {cruise }} \text { [min] }\end{array}$} & \multicolumn{4}{|c|}{ Emission } \\
\hline & & & & $E_{\mathrm{NO}_{\mathrm{x}}}[\mathrm{kg}]$ & $E_{\mathrm{CO}}[\mathrm{kg}]$ & $E_{\mathrm{HC}}[\mathrm{kg}]$ & $E_{\mathrm{CO}_{2}}[\mathrm{~kg}]$ \\
\hline No 5 (Figure 5): reference & 64 & 4 & 28.10 & 28.25 & 1.89 & 0.2432 & 2593 \\
\hline No 6 (Figure 5): optimised & 61 & 4 & 29.10 & 29.26 & 1.96 & 0.2518 & 2685 \\
\hline No 7 (Figure 6): optimised & 63 & 2 & 27.62 & 27.77 & 1.86 & 0.2390 & 2685 \\
\hline No 8 (Figure 6): optimised & 61 & 1 & 26.89 & 27.02 & 1.80 & 0.2326 & 2480 \\
\hline
\end{tabular}

Table 7. The difference (numerical and percentage) between flight parameters (its duration) and the emission of selected pollutants in the exhausts on optimized trajectory No 8 in relation to the non-optimized trajectory No 5 (non-optimized trajectory $=100 \%$ ) on the Rzeszow-Gdansk route

\begin{tabular}{|c|c|c|c|c|c|c|c|c|c|}
\hline$t_{\text {cruise }}[\mathrm{min}]$ & $t_{\text {cruise }}[\%]$ & $E_{\mathrm{NO}_{\mathrm{x}}}[\mathrm{kg}]$ & $E_{\mathrm{NO}_{\mathrm{x}}}[\%]$ & $E_{\mathrm{CO}}[\mathrm{kg}]$ & $E_{\mathrm{CO}}[\%]$ & $E_{\mathrm{HC}}[\mathrm{kg}]$ & $E_{\mathrm{HC}}[\%]$ & $E_{\mathrm{CO}_{2}}[\mathrm{~kg}]$ & $E_{\mathrm{CO}_{2}}[\%]$ \\
\hline-1.21 & -4.3 & -1.23 & -4.35 & -0.09 & -4.76 & -0.0106 & -4.36 & -113 & -4.36 \\
\hline
\end{tabular}

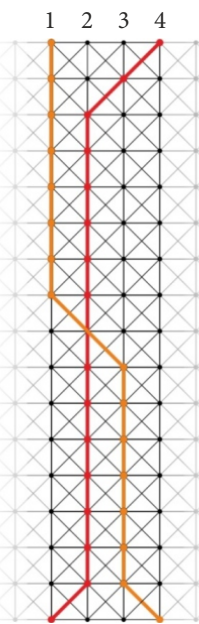

61626364

Figure 6. Trajectories with higher total emissions for the flight with wind (No 1 - red: reference, No 2 - orange: optimised)

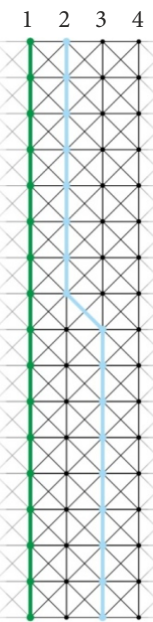

$616263 \quad 64$

Figure 7. Trajectories with the lowest total emissions for the flight with wind (No 3 - blue: optimised, No 4 - green: optimised)

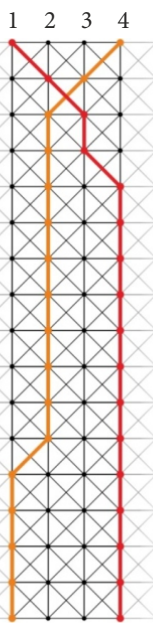

$616263 \quad 64$

Figure 8. Trajectories with higher total emissions for the flight upwind (No 5 - red: reference, No 6 - orange: optimised)

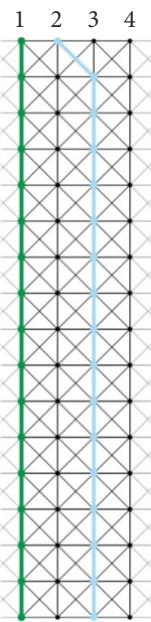

$6162 \quad 63 \quad 64$

Figure 9. Trajectories with the lowest total emissions for the flight upwind (No 7 - blue: optimised, No 8 - green: optimised) 
As it can be noticed, the percentage differences between different substances emitted for the optimized trajectory are very similar and directly depend on the difference in flight time.

Based on the above analyses, a number of conclusions can be drawn:

1. the trajectory optimization has a significant impact on the reduction of pollutants emission in the jet engines exhausts. Based on the dependencies described by the Formulas (1)-(12), it can be noticed that the emission depends directly on the engine's run time, and the shorter the run time (shorter flight duration), the lower the emission;

2. flight duration depends on many factors. The most significant one is the direction and speed of wind, as they determine whether the flight duration will be shortened or lengthened. Another important factor is the trajectory of the flight charted between the subsequent vertices on the edges of the graph. In general, the weights of the edges of the graph determine, which path will be the most favourable in terms of a given criterion. In the analysed case, the weights of the edges of the graph directly depend on the direction and speed of the wind. These edges that have the lowest weights represent the most favourable conditions for the passage. As a result of the optimisation, the shortest flight duration is obtained. Based on the designated trajectories shown in the Figures 3-6, it can be concluded that the trajectory from point $A$ to $B$ does not have to coincide with the trajectory from point B to A, assuming even identical meteorological conditions;

3. optimized flight trajectories between the same vertices but with opposite flight directions do not have to be symmetrical;

4. the longer the route to be covered in the cruise phase, the greater decrease in emission of pollutants can be obtained when the presented optimization methodology is applied.

\section{Conclusions}

The aim of the work was to develop and verify the model of emission of harmful substances present in the jet engines exhausts of a passenger jet aircraft in the cruise phase.

The model of emission of pollutants in the jet engines exhausts of the aircraft in the cruise phase, presented in the paper, allows determining the emission of $\mathrm{NO}_{\mathrm{x}}$, $\mathrm{CO}, \mathrm{HC}$ and $\mathrm{CO}_{2}$ in by-pass jet engines of a passenger jet aircraft in its cruise phase. As the model is based on commonly known procedures for determining aircraft performance during a flight, it can be used for jet passenger jet aircraft, both business aviation and larger aircraft, taking into account the specificity of their operation. The obtained results were subjected to an experimental and numerical verification, which proved the accuracy of the adopted computational method.

The model was verified by its application to optimize the aircraft's trajectory in terms of minimizing emissions, which was done using the Dijkstra's algorithm. Application of the Dijkstra's algorithm enables to indicate the best flight trajectory in terms of minimizing emissions of harmful compounds in jet engines exhausts. Based on the flight duration, the weights for the individual edges of the graph were determined. The results of the conducted research show that the impact of wind on the trajectory is significant - the wind influences the duration of the flight. It should be noted that in the optimization of aircraft flight trajectories, edge weights can not only determine emission values, but also other parameters (traffic congestion, existence of storm clouds, etc.). This indicates further research directions, such as a long-distance flight analysis, as well as flight analysis at various operational altitudes, both in terms of minimising emission of pollutants in jet engines exhausts. Analyses of the influence of other factors on the trajectory of the flight will be carried out in further studies.

All in all, it can be stated that the developed model of emission is useful - it allows to obtain data that can be used in further analyses and research, e.g. on multicriteria optimization of flight trajectory in the cruising phase, from which the emission minimization will be one of the components.

\section{Funding}

This work was supported by funding under the SESAR Joint Undertaking under the EU's Horizon 2020 research and innovation programme under grant agreement No 734129.

\section{Author contributions}

Jowita Pawluczy and Andrzej Majka were responsible for the literature review and preparing "Introduction".

Małgorzata Pawlak, Michal Kuzniar, Andrzej Majka and Jowita Pawluczy wrote "State-of-the-art" and "Conclusions" and took part in the data processing.

Michal Kuzniar and Małgorzata Pawlak made the computations and wrote "Developing a model of exhausts emission for a jet aircraft in cruise phase".

Małgorzata Pawlak, Michal Kuzniar and Andrzej Majka wrote "Verification of the developed model of emission".

\section{Disclosure statement}

We, the authors, declare that we do not have any competing financial, professional nor personal interests from other parties.

\section{References}

Antoine, N. E.; Kroo, I. M. 2004. Aircraft optimization for minimal environmental impact, Journal of Aircraft 41(4): 790-797. https://doi.org/10.2514/1.71

Archer, L. J. 2001. Aircraft Emissions and the Environment. Oxford Institute for Energy Studies. $163 \mathrm{p}$.

Bower, G. C.; Kroo, I. M. 2008. Multi-objective aircraft optimization for minimum cost and emissions over specific route 
networks, in 26th Congress of International Council of the Aeronautical Sciences Including the 8th AIAA Aviation Technology, Integration, and Operations (ATIO) Conference, 14-19 September 2008, Anchorage, Alaska, US, 1-23.

https://doi.org/10.2514/6.2008-8905

Brusow, W.; Klepacki, Z.; Majka, A. 2007. Airports and Facilities Data Base. European Personal Air Transportation System (EPATS) Technical Report. Project No ASA6CT-2006-044549.

Dijkstra, E. W. 1959. A note on two problems in connexion with graphs, Numerische Mathematik 1: 269-271.

https://doi.org/10.1007/BF01386390

EASA. 2013. EASA Type-Certificate Data Sheet. Rolls-Royce Deutschland Ltd \& Co KG Tay Series Engines. Number: E.063 Issue: 04. European Aviation Safety Agency (EASA). 13 p. Available from Internet: https://www.easa.europa.eu/ sites/default/files/dfu/EASA-TCDS-E.063_Rolls--Royce_ Deutschland_Tay_Series_engines-04-18062013.pdf

EASA. 2018. ICAO Aircraft Engine Emissions Databank. European Aviation Safety Agency (EASA). Available from Internet: https://www.easa.europa.eu/easa-and-you/environment/ icao-aircraft-engine-emissions-databank

Elbir, T. 2008. Estimation of engine emissions from commercial aircraft at a midsized Turkish airport, Journal of Environmental Engineering 134(3): 210-215.

https://doi.org/10.1061/(ASCE)0733-9372(2008)134:3(210)

EUROCONTROL. 2018. European Organisation for the Safety of Air Navigation. Available from Internet:

https://www.eurocontrol.int

EUROCONTROL. 2016a. EUROCONTROL Seven-Year Forecast: Flight Movements and Service Units 2016-2022. Edition Number: 16/09/26-98. European Organisation for the Safety of Air Navigation (EUROCONTROL). 92 p. Available from Internet: https://www.eurocontrol.int/sites/default/files/content/ documents/official-documents/forecasts/seven-year-flightsservice-units-forecast-2016-2022-september-2016.pdf

EUROCONTROL. 2016b. Free Route Airspace developments: for a Route-Free European Network. European Organisation for the Safety of Air Navigation (EUROCONTROL). 32 p. Available from Internet: https://www.eurocontrol.int/sites/default/ files/2019-06/free-route-airspace-brochure-20161216.pdf

Flightradar24. 2018. Flightradar24 Flight Tracker. Available from Internet: https://www.flightradar24.com

Garrison, M.; DuBois, D.; Baughcum, S. 2003. Aircraft emission inventories and scenarios, in Ultra-Efficient Engine Technology (UEET) Forum, 27-29 October 2003, Westlake, OH, US.

Głowacki, P.; Szczeciński, S. 2013. Transport lotniczy: zagrożenia ekologiczne oraz sposoby ich ograniczania. Wydawnictwa Naukowe Instytutu Lotnictwa, Warszawa. 121 s. (in Polish).

Hamy, A.; Murrieta-Mendoza, A.; Botez, R. 2016. Flight trajectory optimization to reduce fuel burn and polluting emissions using a performance database and ant colony optimization algorithm, in AEGATS'2016: Advanced Aircraft Efficiency in a Global Air Transport System, 12-14 April 2016, Paris, France, 1-9.

ICAO. 2008. Environmental Protection. Annex 16: to the Convention on International Civil Aviation. Volume II: Aircraft Engine Emissions. International Civil Aviation Organization (ICAO). 97 p.

IPCC. 1997. Revised 1996 IPCC Guidelines for National Greenhouse Gas Inventories. Volume 3: Reference Manual. Intergovernmental Panel on Climate Change (IPCC). Available from Internet:

https://www.ipcc-nggip.iges.or.jp/public/gl/invs6.html
Jeż, M. 2009. Transport lotniczy a zrównoważony rozwój. Biblioteka Naukowa Instytutu Lotnictwa, Wydawnictwa Naukowe Instytutu Lotnictwa, Warszawa. 176 s. (in Polish).

Khardi, S.; Kurniawan, J. 2012. Combined effect of Aircraft Noise and Pollutant Emissions in the Intermediate Atmospheric Layers. International Joint Research Project 2010-2012. University of Indonesia, Indonesia / INRETS, France. INRETS-LTE Report No 1010. 78 p.

Kim, B. Y.; Fleming, G. G.; Lee, J. J.; Waitz, I. A.; Clarke, J.-P.; Balasubramanian, S.; Malwitz, A.; Klima, K.; Locke, M.; Holsclaw, C. A.; Maurice, L. Q.; Gupta, M. L. 2007. System for assessing aviation's global emissions (SAGE), part 1: model description and inventory results, Transportation Research Part D: Transport and Environment 12(5): 325-346.

https://doi.org/10.1016/j.trd.2007.03.007

Kopecki, G.; Pęczkowski, M.; Rogalski, T. 2017. Rzykładowy algorytm automatycznego wyznaczania trasy przelotu $\mathrm{w}$ przestrzeni lotów swobodnych, Autobusy (6): 1219-1224. (in Polish).

Masiol, M.; Harrison, R. M. 2014. Aircraft engine exhaust emissions and other airport-related contributions to ambient air pollution: a review, Atmospheric Environment 95: 409-455. https://doi.org/10.1016/j.atmosenv.2014.05.070

PANSA. 2018. Polish Air Navigation Services Agency (PANSA). Available from Internet: https://www.pansa.pl

Pawlak, M.; Kuźniar, M. 2018. Analysis of the wind dependent duration of the cruise phase on jet engine exhaust emissions, Journal of KONES Powertrain and Transport 25(3): 371-376.

Pawlak, M.; Majka, A.; Kuźniar, M.; Pawluczy, J. 2018a. Analysis of wind impact on emission of selected exhaust compounds in jet engines of a business jet aircraft in cruise phase, Combustion Engines 173(2): 55-60. https://doi.org/10.19206/CE-2018-209

Pawlak, M.; Majka, A.; Kuźniar, M.; Pawluczy, J. 2018b. Emission of selected exhaust compounds in jet engines of a jet aircraft in cruise phase, Combustion Engines 173(2): 67-72. https://doi.org/10.19206/CE-2018-211

Penner, J. E.; Lister, D. H.; Griggs, D. J.; Dokken, D. J.; McFarland, M. (Eds.). 1999. Aviation and the Global Atmosphere. Intergovernmental Panel on Climate Change. 373 p. Available from Internet: https://www.ipcc.ch/report/aviation-and-theglobal-atmosphere-2

Pratap, R. 2016. Getting Started with MATLAB: a Quick Introduction for Scientists and Engineers. Oxford University Press. $320 \mathrm{p}$.

Ramanathan, V.; Feng, Y. 2009. Air pollution, greenhouse gases and climate change: Global and regional perspectives, Atmospheric Environment 43(1): 37-50.

https://doi.org/10.1016/j.atmosenv.2008.09.063

Schaefer, M.; Bartosch, S. 2013. Overview on Fuel Flow Correlation Methods for the Calculation of $\mathrm{NO}_{x}, \mathrm{CO}$ and HC Emissions and Their Implementation into Aircraft Performance Software. Deutsches Zentrum für Luft- und Raumfahrt (DLR), Institut für Antriebstechnik, Köln. 15 p.

Schäfer, A. W.; Waitz, I. A. 2014. Air transportation and the environment, Transport Policy 34: 1-4. https://doi.org/10.1016/j.tranpol.2014.02.012

Serafino, G. 2014. Multi-objective trajectory optimization to reduce aircraft emissions in case of unforeseen weather events, in 29th Congress of the International Council of the Aeronautical Sciences, 7-12 September 2014, St. Petersburg, Russia, 1-9. Available from Internet: https://www.icas.org/ICAS_ARCHIVE/ICAS2014/data/papers/2014_0338_paper.pdf 
SESAR. 2018. Single European Sky ATM Research (SESAR). Available from Internet: https://www.sesarju.eu

Singh, V. 2017. Fuel consumption minimization of transport aircraft using real-coded genetic algorithm, Proceedings of the Institution of Mechanical Engineers, Part G: Journal of Aerospace Engineering 232(10): 1925-1943.

https://doi.org/10.1177/0954410017705899

Singh, V; Sharma, S. K. 2014. Evolving base for the fuel consumption optimization in Indian air transport: application of structural equation modelling, European Transport Research Review 6(3): 315-332.

https://doi.org/10.1007/s12544-014-0134-4

WHO. 2006. Air Quality Guideline: Global Update 2005: Particulate Matter, Ozone, Nitrogen Dioxide and Sulfur Dioxide. World Health Organization (WHO). 496 p. Available from Internet: http://www.euro.who.int/__data/assets/pdf_ file/0005/78638/E90038.pdf

Wilson, D. G.; Korakianitis, T. 2014. The Design of High-Efficiency Turbomachinery and Gas Turbines. MIT Press. 624 p. https://doi.org/10.7551/mitpress/9940.001.0001

Windy. 2018. Meteorological Maps. Available from Internet: https://www.windy.com 